\title{
Access to health care among status Aboriginal people with chronic kidney disease
}

\author{
Song Gao MSc, Braden J. Manns MD MSc, Bruce F. Culleton MD, Marcello Tonelli MD SM, \\ Hude Quan PhD, Lynden Crowshoe MD, William A. Ghali MD MPH, Lawrence W. Svenson BSc, \\ Sofia Ahmed MD MMSc, Brenda R. Hemmelgarn PhD MD, for the Alberta Kidney Disease Network
}

$\infty$ See related commentary by Peiris and colleagues, page 985

\section{ABSTRACT}

Background: Ethnic disparities in access to health care and health outcomes are well documented. It is unclear whether similar differences exist between Aboriginal and non-Aboriginal people with chronic kidney disease in Canada. We determined whether access to care differed between status Aboriginal people (Aboriginal people registered under the federal Indian Act) and non-Aboriginal people with chronic kidney disease.

Methods: We identified 106511 non-Aboriginal and 1182 Aboriginal patients with chronic kidney disease (estimated glomerular filtration rate less than $60 \mathrm{~mL} / \mathrm{min} / 1.73 \mathrm{~m}^{2}$ ). We compared outcomes, including hospital admissions, that may have been preventable with appropriate outpatient care (ambulatory-care-sensitive conditions) as well as use of specialist services, including visits to nephrologists and general internists.

Results: Aboriginal people were almost twice as likely as non-Aboriginal people to be admitted to hospital for an ambulatory-care-sensitive condition (rate ratio 1.77, 95\% confidence interval $[\mathrm{Cl}] 1.46-2.13)$. Aboriginal people with severe chronic kidney disease (estimated glomerular filtration rate $<30 \mathrm{~mL} / \mathrm{min} / 1.73 \mathrm{~m}^{2}$ ) were $43 \%$ less likely than non-Aboriginal people with severe chronic kidney disease to visit a nephrologist (hazard ratio $0.57,95 \% \mathrm{Cl} 0.39-0.83$ ). There was no difference in the likelihood of visiting a general internist (hazard ratio $1.00,95 \% \mathrm{Cl} 0.83-1.21$ ).

Interpretation: Increased rates of hospital admissions for ambulatory-care-sensitive conditions and a reduced likelihood of nephrology visits suggest potential inequities in care among status Aboriginal people with chronic kidney disease. The extent to which this may contribute to the higher rate of kidney failure in this population requires further exploration.

Une version française de ce résumé est disponible à l'adresse www.cmaj.ca/cgi/content/full/179/10/1007/DC1

CMAJ 2008;179(10):1007-12

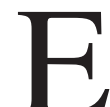
thnic disparities in access to health care are well documented; ${ }^{1,2}$ however, the majority of studies include black and Hispanic populations in the United States. The poorer health status and increased mortality among Aboriginal populations than among non-Aboriginal popula- tions, ${ }^{3,4}$ particularly among those with chronic medical conditions, ${ }^{5,6}$ raise the question as to whether there is differential access to health care and management of chronic medical conditions in this population.

The prevalence of end-stage renal disease, which commonly results from chronic kidney disease, is about twice as common among Aboriginal people as it is among nonAboriginal people. ${ }^{7,8}$ Given that the progression of chronic kidney disease can be delayed by appropriate therapeutic interventions ${ }^{9,10}$ and that delayed referral to specialist care is associated with increased mortality, ${ }^{11,12}$ issues such as access to health care may be particularly important in the Aboriginal population. Although previous studies have suggested that there is decreased access to primary and specialist care in the Aboriginal population, ${ }^{13-15}$ these studies are limited by the inclusion of patients from a single geographically isolated region, ${ }^{13}$ the use of survey data, ${ }^{14}$ and the inability to differentiate between different types of specialists and reasons for the visit. ${ }^{15}$

In addition to physician visits, admission to hospital for ambulatory-care-sensitive conditions (conditions that, if managed effectively in an outpatient setting, do not typically result in admission to hospital) has been used as a measure of access to appropriate outpatient care. ${ }^{16,17}$ Thus, admission to hospital for an ambulatory-care-sensitive condition reflects a potentially preventable complication resulting from inadequate access to care. Our objective was to determine whether access to health care differs between status Aboriginal (Aboriginal people registered under the federal Indian Act) and non-Aboriginal people with chronic kidney disease. We assess differences in care by 2 measures: admission to hospital for an ambulatory-caresensitive condition related to chronic kidney disease; and receipt of nephrology care for severe chronic kidney disease as recommended by clinical practice guidelines. ${ }^{18}$

From the Departments of Medicine, Division of Nephrology (Gao, Manns, Culleton, Ahmed, Hemmelgarn), Community Health Services (Manns, Quan, Ghali, Svenson, Hemmelgarn), Family Medicine (Crowshoe) and General Internal Medicine (Ghali), and the Centre for Health and Policy Studies (Quan, Ghali), University of Calgary, Calgary, Alta.; The Department of Medicine, Division of Nephrology (Tonelli), University of Alberta; and Public Health Surveillance and Environmental Health, Alberta Health and Wellness (Svenson), Edmonton, Alta. 


\section{Methods}

\section{Study population and data sources}

We used computerized laboratory data from 6 of the 9 geographically defined health regions in Alberta, Canada, to identify the study cohort. Over $80 \%$ of the province's population lives in these 6 regions. We included residents of Alberta aged 20 and older who had 1 or more outpatient measurement of their serum creatinine level made during a 1-year period from July 1, 2003, to June 30, 2004. We excluded patients with a clinically implausible serum creatinine measurement $(<25 \mu \mathrm{mol} / \mathrm{L})$. Because we were interested in stable chronic kidney disease and to avoid including episodes of acute renal failure, we also excluded laboratory measurements associated with a hospital admission. The date of the first serum creatinine measurement was used as the index date.

The study cohort was linked to provincial administrative health data to identify status Aboriginal people as well as obtain details regarding health care resource use. The term "status Aboriginal" refers to any individual registered under the federal Indian Act. Status Aboriginal people are identifiable within the Alberta Health Care Insurance Plan Registry. The registry was searched from Apr. 1, 1993, to Mar. 31, 2005, and any individual with a status Aboriginal indicator at any time was classified as "status Aboriginal" (hereinafter referred to as Aboriginal). All other people were classified as non-Aboriginal. Aboriginal people who are not registered under federal Indian Act (e.g., unregistered Aboriginal and Metis people) were included in the non-Aboriginal group. Ac- cording to the 2001 census, about $70 \%$ of the Aboriginal population in Alberta is status Aboriginal. ${ }^{19}$

We excluded patients who had received a kidney transplant (identified from Provincial Renal Program databases) ${ }^{20}$ and those receiving long-term dialysis (identified from administrative data $^{21}$ ) before their index date. Patients with diabetes mellitus were identified by use of a validated administrative algorithm. ${ }^{22}$ We estimated socio-economic status using the neighbourhood income-per-person equivalent, an estimate of household income adjusted for household size based on data provided by the 2001 Canadian census. ${ }^{23} \mathrm{We}$ obtained location of residence, based on community size, from census data. Rural residence was defined as living in a community of less than 10000 people. ${ }^{7,24}$

This study was approved by the institutional review board at the University of Calgary.

\section{Measure of kidney function}

We estimated glomerular filtration rate using the abbreviated prediction equation from the Modification of Diet in Renal Disease study. This equation includes variables for age, sex, black ethnic background (v. white) and serum creatinine measurement. ${ }^{25}$ Although ethnic background was not available from the data sources, less than $1 \%$ of the Alberta population is black. Therefore, the impact at the population level of eliminating ethnic background from the equation was expected to be minimal. Preliminary studies have validated the use of this equation in the Aboriginal population ${ }^{26}$ and in a community-based population with chronic kidney disease. ${ }^{27}$ We standardized the serum creatinine measurements made at

Table 1: Baseline characteristics of Aboriginal and non-Aboriginal patients with chronic kidney disease

\begin{tabular}{|c|c|c|c|}
\hline \multirow[b]{2}{*}{ Characteristic } & \multicolumn{2}{|c|}{ No. $(\%)$ of patients* } & \multirow[b]{2}{*}{$p$ value $\neq$} \\
\hline & $\begin{array}{c}\text { Aboriginalt } \\
(n=1182)\end{array}$ & $\begin{array}{c}\text { Non-Aboriginal } \\
(n=106511)\end{array}$ & \\
\hline Age, yr, median (IQR) & $60(50-70)$ & $71(60-80)$ & $<0.001$ \\
\hline Female & $743(63.0)$ & $67741(63.6)$ & 0.61 \\
\hline Estimated GFR , median, mL/min/1.73 $\mathrm{m}^{2}$ (IQR) & $50(38-56)$ & $52(44-57)$ & $<0.001$ \\
\hline Estimated GFR, $\mathrm{mL} / \mathrm{min} / 1.73 \mathrm{~m}^{2}$ & & & $<0.001$ \\
\hline $30-59$ & $1014(85.8)$ & 99594 (93.5) & \\
\hline $15-29$ & $105(8.9)$ & $5907 \quad(5.6)$ & \\
\hline$<15$ & $63(5.4)$ & $1010(1.0)$ & \\
\hline Diabetes mellitus & $500(42.3)$ & $19929(18.7)$ & $<0.001$ \\
\hline Rural residence & $550(46.5)$ & $14208(13.3)$ & $<0.001$ \\
\hline Median household income & $n=1054$ & $n=102357$ & $<0.001$ \\
\hline 1st quintile (lowest) & $566(53.7)$ & $20613(20.1)$ & \\
\hline 2nd quintile & $198(18.8)$ & $20948(20.5)$ & \\
\hline 3rd quintile & $143(13.6)$ & $21231(20.7)$ & \\
\hline 4th quintile & $73(7.0)$ & $18931(18.5)$ & \\
\hline 5th quintile (highest) & $74(7.0)$ & $20634(20.2)$ & \\
\hline
\end{tabular}

Note: GFR = glomerular filtration rate, IQR = interquartile range

*Unless stated otherwise.

tIncludes people registered under the federal Indian Act (status Aboriginal). Aboriginal people who are not registered under the federal Indian Act (e.g., unregistered Aboriginal and Metis people) were included in the non-Aboriginal group.

‡Determined by use of a rank-sum test for medians and $\chi^{2}$ test for proportions. 
laboratories across the province to a single central laboratory. A correction factor was applied when necessary to ensure a province-wide standardization of values. As an indirect calibration, we compared the estimated glomerular filtration rates obtained by use of this method with those from one of the largest laboratories in the province, which uses an isotopedilution mass spectrometry reference standard, and with the new Modification of Diet in Renal Disease study equation. ${ }^{28}$ Similar estimates were obtained with each method.

We used the first serum creatinine measurement in the 1year accrual period (July 1, 2003, to June 30, 2004) to determine each patient's index estimated glomerular filtration rate. We categorized the index rate according to the Kidney Disease Outcome Quality Initiative classification ( $\geq 90,60-89$, $\left.30-59,15-29,<15 \mathrm{~mL} / \mathrm{min} / 1.73 \mathrm{~m}^{2}\right) .{ }^{18}$ Chronic kidney disease was defined as an estimated glomerular filtration rate of less than $60 \mathrm{~mL} / \mathrm{min} / 1.73 \mathrm{~m}^{2}$.

\section{Measures of access to care}

We evaluated access to care during the study period (date of index measurement of estimated glomerular filtration rate to Mar. 31, 2005) by use of 2 measures: admission to hospital for an ambulatory-care-sensitive condition related to chronic kidney disease, and likelihood of a nephrology visit for severe chronic kidney disease. Ambulatory-care-sensitive conditions can typically be managed effectively in an ambulatory setting; thus, admission to hospital for such a condition reflects a potentially preventable complication resulting from inadequate access to or quality of outpatient health care. ${ }^{16,17}$ We used a modified Delphi process (with 3 Delphi rounds) and an expert panel of 12 nephrologists to identify chronic kidney disease specific and relevant ambulatory-care-sensitive conditions based on the primary discharge diagnosis. Cause-specific hospital admissions were determined by use of hospital discharge coding performed by trained individuals in accordance with the International Classification of Disease, ninth revision, clinical modification (ICD-9-CM) and the International Statistical Classification of Diseases and Related Health Problems, tenth revision, Canada (ICD-10 CA) (Appendix 1, available at www.cmaj.ca/cgi/content/full/179/10/1007/DC2).

The second measure of access to care, nephrology visit for severe chronic kidney disease (estimated glomerular fil- tration rate $<30 \mathrm{~mL} / \mathrm{min} / 1.73 \mathrm{~m}^{2}$ ), was based on national guidelines for chronic kidney disease management, ${ }^{18}$ and was defined as at least 1 outpatient visit to a nephrologist after the index measurement of estimated glomerular filtration rate. In a secondary analysis, we also explored the relation between being Aboriginal and likelihood of an outpatient visit to a general internist.

\section{Statistical analysis}

We used $\chi^{2}$ and nonparametric (rank-sum) tests to compare differences in baseline characteristics for Aboriginal and nonAboriginal people during the study period. For hospital admission rates for ambulatory-care-sensitive conditions related to chronic kidney disease, we counted all events for patients with multiple hospital admissions. Person-time of follow-up was based on out-of-hospital time only (i.e., subtracting the number of days spent in-hospital from the total follow-up), with patient's data censored at death, emigration from the province and end of the study period. We used a Poisson regression model to determine the association between ethnic background and risk of admission to hospital for an ambulatory-caresensitive condition related to chronic kidney disease, after adjustment for age, sex, diabetes, baseline estimated glomerular filtration rate and hospital admissions for non-ambulatorycare-sensitive conditions. In a sensitivity analysis, we used a Cox proportional hazards model to determine the association between ethnic background and risk of first hospitalization for an ambulatory-care-sensitive condition. Cox proportional hazards models were used to determine the adjusted association between ethnic background and likelihood of an outpatient nephrologist visit or a general internist visit for patients with severe chronic kidney disease. Poisson and Cox regression models were adjusted for sex, age, baseline estimated glomerular filtration rate and diabetes. Finally, in a second analysis, we included a model that also adjusted for household income and rural location of residence. We decided a priori not to include these variables in our primary analysis because they may be considered a component of ethnic background and result in over-adjustment. ${ }^{29}$ Rate ratios (RR) and hazard ratios (HR) greater than 1 in these analyses indicate increased risk for the outcome. Assumptions for the Cox and Poisson regression models were tested and met.

Table 2: Rates and rate ratios for admission to hospital for ambulatory-care-sensitive conditions among Aboriginal and non-Aboriginal people with chronic kidney disease

Rate per 100 person-years $(95 \% \mathrm{Cl})$

\begin{tabular}{lcccc}
\cline { 2 - 3 } Analysis & Aboriginal* & Non-Aboriginal & Rate ratio $(95 \% \mathrm{Cl})$ & $p$ value \\
\hline Unadjusted & $7.7(6.4-9.2)$ & $2.8(2.7-2.9)$ & $2.72(2.27-3.27)$ & $<0.001$ \\
Adjustedt & $2.8(2.3-3.4)$ & $1.6(1.5-1.6)$ & $1.77(1.46-2.13)$ & $<0.001$ \\
Adjusted $\neq$ & $2.4(2.0-3.0)$ & $1.5(1.4-1.6)$ & $1.58(1.30-1.92)$ & $<0.001$ \\
\hline
\end{tabular}

Note: $\mathrm{Cl}=$ confidence interval.

*Includes people registered under the federal Indian Act (status Aboriginal). Aboriginal people who are not registered under the federal Indian Act (e.g., unregistered Aboriginal and Metis people) were included in the non-Aboriginal group.

†Adjusted for age, sex, diabetes, baseline estimated glomerular filtration rate and admission to hospital for a non-ambulatory-care-sensitive condition.

$\ddagger$ Adjusted for age, sex, diabetes, baseline estimated glomerular filtration rate, median household income quintile, admission to hospital for a non-ambulatory-

care-sensitive condition, and rural location of residence. 


\section{Results}

\section{Study participants}

In total, 676660 patients had at least 1 outpatient serum creatinine measurement. We excluded $129(0.02 \%)$ patients who had a serum creatinine level less than $25 \mu \mathrm{mol} / \mathrm{L}, 2139$ (0.3\%) who were receiving long-term dialysis, 739 (0.1\%) who had received a kidney transplant before their index date and 565960 $(83.6 \%)$ who had an estimated glomerular filtration rate greater than $60 \mathrm{~mL} / \mathrm{min} / 1.73 \mathrm{~m}^{2}$. Thus, our study included included 107693 people with chronic kidney disease. Of these, 1182 (1.1\%) were status Aboriginal people. The duration of followup was similar for the Aboriginal (median 1.37 years) and nonAboriginal groups (median 1.39 years). Compared with nonAboriginal patients, Aboriginal patients were younger and were more likely to live in a rural location in the lowest quintile of median household income (Table 1). Aboriginal people were also more likely than non-Aboriginal people to have diabetes mellitus and more severe kidney dysfunction.

\section{Access to care}

In total, $6.2 \%$ of Aboriginal people and $2.7 \%$ of nonAboriginal people had at least 1 hospital admission for an ambulatory-care-sensitive condition related to chronic kidney disease $(p<0.001)$. The number of hospital admissions among those with at least 1 hospital admission was similar for Aboriginal people (median 1, interquartile range 1-2) and non-Aboriginal people (median 1, interquartile range 1-1). After adjustment for age, sex, baseline estimated glomerular filtration rate, non-ambulatory-care-sensitive hospital admissions and diabetes, Aboriginal people were almost twice as likely as non-Aboriginal people to have been admitted to hospital for an ambulatory-care-sensitive condition (RR 1.77, 95\% confidence interval [CI] 1.46-2.13). In a model that also adjusted for median household income and rural location of residence, the rate ratio of hospital admissions for an ambulatory-care-sensitive condition was about 1.5 times higher among Aboriginal people than among non-Aboriginal people (RR 1.58, 95\% CI 1.30-1.92) (Table 2) (Full model available online in Appendix 2 at www.cmaj.ca/cgi/content /full/179/10/1007/DC2.)

A similar proportion of Aboriginal (17.3\%) and non-
Aboriginal patients $(16.3 \%)$ had at least 1 outpatient visit to a nephrologist during the study period $(p=0.75)$. Among these patients, the mean index estimated glomerular filtration rate was lower among Aboriginal people (mean $18.33 \mathrm{~mL} / \mathrm{min} / 1.73$ $\mathrm{m}^{2}$, standard deviation [SD] $7.54 \mathrm{~mL} / \mathrm{min} / 1.73 \mathrm{~m}^{2}$ ) than among non-Aboriginal people (mean $22.33 \mathrm{~mL} / \mathrm{min} / 1.73 \mathrm{~m}^{2}$, SD 6.17 $\mathrm{mL} / \mathrm{min} / 1.73 \mathrm{~m}^{2}$ ).

Aboriginal people were $43 \%$ less likely than nonAboriginal people to have visited a nephrologist (adjusted HR $0.57,95 \%$ CI 0.39-0.83) (Table 3). Age was the most influential confounder in this analysis: every 1-year increase in age was associated with a $2 \%$ reduction in the likelihood of a nephrologist visit among Aboriginal people (HR for age 0.98, 95\% CI 0.97-0.98). Tests for interaction between age, sex, estimated glomerular filtration rate, diabetes and ethnic background were not significant, suggesting that the association between ethnic background and likelihood of a nephrologist visit was not influenced by these characteristics. In a second adjusted analysis that included location of residence and median household residence, there was a nonsignificant decrease in the likelihood of a nephrologist visit among Aboriginal people compared with non-Aboriginal people (adjusted HR 0.68, 95\% CI 0.45-1.04, $p=0.007$ ) (Table 3).

During the study period a significantly greater percentage of Aboriginal patients had at least 1 outpatient visit to a general internist compared with non-Aboriginal people $(75.6 \%$ v. $55.8 \%$, $p<0.001)$. However, after adjustment, there was no association between ethnic background and likelihood of a visit to a general internist for severe chronic kidney disease (Table 4).

A similar percentage of Aboriginal (96.5\%) and nonAboriginal people $(95.8 \%)$ had at least 1 outpatient visit to a general practitioner during the study period $(p=0.23)$. A much greater percentage of Aboriginal people (72.2\%) than non-Aboriginal people $(44.0 \%)$ had at least 1 visit to an emergency department during the study period $(p<0.001)$.

\section{Interpretation}

Our results suggest that there are differences in the care received by status Aboriginal and non-Aboriginal people with chronic kidney disease. First, Aboriginal people with chronic kidney disease do access the health care system, as shown by

Table 3: Rates and hazard ratios for likelihood of an outpatient visit to a nephrologist for Aboriginal and non-Aboriginal people with severe chronic kidney disease*

\begin{tabular}{|c|c|c|c|c|}
\hline \multirow[b]{2}{*}{ Analysis } & \multicolumn{2}{|c|}{ Rate per 100 person years $(95 \% \mathrm{Cl})$} & \multirow[b]{2}{*}{ Hazard ratio $(95 \% \mathrm{Cl})$} & \multirow[b]{2}{*}{$p$ value } \\
\hline & Aboriginalt & Non-Aboriginal & & \\
\hline Unadjusted & $15.6(10.9-22.5)$ & $15.3(14.5-16.2)$ & $1.02(0.71-1.47)$ & 0.92 \\
\hline Adjusted $¥$ & $7.8(5.4-11.3)$ & $13.8(13.0-14.8)$ & $0.57(0.39-0.83)$ & 0.003 \\
\hline Adjusted§ & $9.3(6.1-14.0)$ & $13.5(12.6-14.4)$ & $0.68(0.45-1.04)$ & 0.007 \\
\hline
\end{tabular}

Note: $\mathrm{Cl}=$ confidence interval.

*Defined as an estimated glomerular filtration rate less than $30 \mathrm{~mL} / \mathrm{min} / 1.73 \mathrm{~m}^{2}$.

tIncludes people registered under the federal Indian Act (status Aboriginal). Aboriginal people who are not registered under the federal Indian Act

(e.g., unregistered Aboriginal and Metis people) were included in the non-Aboriginal group.

¥Adjusted for age, sex, diabetes and baseline estimated glomerular filtration rate.

$\S$ Adjusted for age, sex, diabetes, baseline estimated glomerular filtration rate, median household income quintile and rural location of residence. 
the use of general practitioner and emergency department services. However, Aboriginal people with chronic kidney disease were almost twice as likely as non-Aboriginal people to be admitted to hospital for an ambulatory-care-sensitive condition related to their chronic kidney disease. In addition, despite national guidelines recommending that people with severe chronic kidney disease visit a nephrologist, we found that Aboriginal people with severe chronic kidney disease were significantly less likely than non-Aboriginal people to have visited a nephrologist.

Although universal coverage for health care in Canada has alleviated insurance-related barriers to care, ${ }^{30}$ our results suggest that other barriers may exist among Aboriginal people, who are less likely than non-Aboriginal people to receive specialized care for chronic kidney disease. This is unlikely to be related to lack of access to the health care system in general, because almost all Aboriginal people in our study had at least 1 visit to a general practitioner. The probability of obtaining a serum creatinine measurement is also unlikely to have influenced these results, as we have reported that Aboriginal people have an increased likelihood of having a serum creatinine measurement compared with non-Aboriginal people. ${ }^{31}$ Decreased access to specialized medical care among Aboriginal people has been reported. ${ }^{14,15}$ Potential barriers, including distance from specialized care, require further study. Delayed referral to a nephrologist for severe chronic kidney disease is not unique to the Aboriginal population and has been reported in other ethnic groups. ${ }^{32,33}$ Given the increased mortality among patients with a late referral to a nephrologist, ${ }^{12,34,35}$ these results suggest suboptimal quality of care in the Aboriginal population and the need for interventions to reduce or eliminate these disparities.

Access to health care is difficult to evaluate, and ambulatorycare-sensitive conditions are commonly used as a measure of access and assessment of performance of the health care system. ${ }^{16,17}$ Barriers in access are complex and include patient, environmental and health system factors. Lower socioeconomic status has been associated with an increased likelihood of hospital admission for an ambulatory-care-sensitive condition in the United States ${ }^{16}$ and an increased frequency of physician visits in Canada. ${ }^{30}$ However, even after adjustment for median household income and rural location of residence,
Aboriginal people were still 50\% more likely than nonAboriginal people to be admitted to hospital for an ambulatorycare-sensitive condition related to their chronic kidney disease. Controlling for socio-economic status and location of residence may result in over-adjustment because these factors are considered to be a component of ethnicity ${ }^{29}$ and may artificially reduce differences in rates hospital admissions for ambulatory-care-sensitive conditions. Thus, in our main analysis, we did not adjust for median household income and rural location of residence. We found a similar increased risk for all-cause hospital admissions among status Aboriginal and non-Aboriginal people (Appendix 3, available at www.cmaj .ca/cgi/content/full/179/10/1007/DC2), which suggests that the increased risk extends beyond ambulatory-care-sensitive conditions related to chronic kidney disease. However, with the present data, we are unable to determine the extent to which patient factors such as compliance with recommended treatments, including attendance at physician appointments, may have influenced the study results.

Although we did not have access to the details of the medical care provided to Aboriginal people with chronic kidney disease, lack of access to specialized care may result in suboptimal use of treatments that reduce the risk of progression of kidney disease, ${ }^{9,10}$ and may contribute to higher rates of end-stage renal disease in this population. This is further supported by our previous study that showed a lower prevalence of all stages of chronic kidney disease but a higher prevalence of more severe chronic kidney disease and increased mortality rates among status Aboriginal people than among non-Aboriginal people. ${ }^{31}$

\section{Limitations}

Our study had several limitations. First, we did not directly calibrate serum creatinine measurements to measurements made at the Cleveland Clinic, where the Modification of Diet in Renal Disease equation for estimated glomerular filtration rate was derived. We did, however, implement a provincewide standardization of serum creatinine measurements that had been indirectly calibrated to the isotope dilution mass spectrometry reference standard using the new Modification of Diet in Renal Disease equation. ${ }^{28}$ Second, we were not able to identify Metis people and non-registered Aboriginal people, which may have resulted in misclassification of some

Table 4: Rates and hazard ratios for likelihood of an outpatient visit to a general internist among Aboriginal and non-Aboriginal people with severe chronic kidney disease*

\begin{tabular}{|c|c|c|c|c|}
\hline \multirow[b]{2}{*}{ Analysis } & \multicolumn{2}{|c|}{ Rate per 100 person years $(95 \% \mathrm{Cl})$} & \multirow[b]{2}{*}{ Hazard ratio $(95 \% \mathrm{Cl})$} & \multirow[b]{2}{*}{$p$ value } \\
\hline & Aboriginalt & Non-Aboriginal & & \\
\hline Unadjusted & $158.3(132.6-188.8)$ & $85.5(82.9-88.3)$ & $1.63(1.36-1.95)$ & $<0.001$ \\
\hline Adjusted $¥$ & $87.6(73.0-105.1)$ & $87.0(84.2-89.9)$ & $1.00(0.83-1.21)$ & 0.97 \\
\hline Adjusted§ & 92.6 (77.1-111.4) & $86.8(84.0-89.7)$ & $1.05(0.88-1.27)$ & 0.55 \\
\hline
\end{tabular}

$\mathrm{Cl}=$ confidence interval.

*Defined as an estimated glomerular filtration rate of less than $30 \mathrm{~mL} / \mathrm{min} / 1.73 \mathrm{~m}^{2}$.

tIncludes people registered under the federal Indian Act (status Aboriginal). Aboriginal people who are not registered under the federal Indian Act

(e.g., unregistered Aboriginal and Metis people) were included in the non-Aboriginal group.

$¥$ Adjusted for age, sex, diabetes and baseline estimated glomerular filtration rate.

§Adjusted for age, sex, diabetes, baseline estimated glomerular filtration rate, median household income quintile and rural location of residence. 
Aboriginal patients as non-Aboriginal. However, given that the majority of the Aboriginal population in Alberta is registered under the federal Indian Act and given the size of the non-Aboriginal population, this potential misclassification would have had minimal impact on our results, and if there was a bias, it would have been toward the null hypothesis. Third, use of laboratory data to define the cohort limited our study to patients who had sought medical care and who had a serum creatinine measurement, which may limit the generalizability of our results. Finally, as with all observational studies, the possibility of residual confounding cannot be excluded. Although we were unable to directly adjust for patient-related factors such as compliance and distance to the nearest nephrologist, we were able to account for key clinical variables, including diabetes and baseline kidney function. The hazard ratios associated with ethnic background and likelihood of a nephrologist visit were substantial, and they are unlikely to be completely negated by adjustment for additional covariables.

\section{Conclusion}

The results of our study suggest potential inequities in care between status Aboriginal people and non-Aboriginal people with chronic kidney disease. The extent to which these inequities may contribute to the higher rates of end-stage kidney failure among the Aboriginal population requires further exploration. Interventions that target these disparities in care are needed.

\section{This article has been peer reviewed.}

\section{Competing interests: None declared.}

Contributors: All of the authors contributed to the conception and design of the study and to the interpretation of the data. Song Gao and Brenda Hemmelgarn performed the analysis and drafted the manuscript. All of the authors revised the article for important intellectual content and approved the final version submitted for publication.

Acknowledgements: Braden Manns, Marcello Tonelli, Hude Quan and Brenda Hemmelgarn are supported by New Investigator Awards from the Canadian Institutes of Health Research. Marcello Tonelli, Hude Quan and Brenda Hemmelgarn are also supported by Population Health Investigator Awards from the Alberta Heritage Foundation for Medical Research. William Ghali is supported by a Government of Canada Research Chair in Health Services Research and by a Health Scholar Award from the Alberta Heritage Foundation for Medical Research.

Funding: This study was supported by an operating grant from the Canadian Institutes of Health Research.

\section{REFERENCES}

1. Chen J, Rathore SS, Radford MJ, et al. Racial differences in the use of cardiac catheterization after acute myocardial infarction. N Engl J Med 2001;344:1443-9.

2. Schneider EC, Zaslavsky AM, Epstein AM. Racial disparities in the quality of care for enrollees in medicare managed care. JAMA 2002;287:1288-94.

3. MacMillan HL, MacMillan AB, Offord DR, et al. Aboriginal health. CMAJ 1996;155:1569-78.

4. Diverty B, Perez C. The health of northern residents. Health Rep 1998;9:49-58.

5. Anand SS, Yusuf S, Jacobs R, et al. Risk factors, atherosclerosis, and cardiovascular disease among Aboriginal people in Canada: the study of health assessment and risk evaluation in Aboriginal peoples (SHARE-AP). Lancet 2001;358:1147-53.

6. Shah BR, Hux JE, Zinman B. Increasing rates of ischemic heart disease in the native population of Ontario, Canada. Arch Intern Med 2000;160:1862-6.

7. Tonelli M, Hemmelgarn B, Manns B, et al. Death and renal transplantation among Aboriginal people undergoing dialysis. CMAJ 2004;171:577-82.

8. Canadian Institutes for Health Information. Treatment of end-stage organ failure in
Canada, 1995 to 2004. Ottawa (ON): The Agency; 2006. Available: http://secure .cihi.ca/cihiweb/products/corr_annual_report_2006_e.pdf (accessed 2008 Sept 30).

9. Brenner BM, Cooper ME, de Zeeuw D, et al. Effects of losartan on renal and cardiovascular outcomes in patients with type 2 diabetes and nephropathy. $N$ Engl $J$ Med 2001;345:861-9.

10. Jafar TH, Schmid CH, Levey AS. Effect of angiotensin-converting enzyme inhibitors on progression of nondiabetic renal disease. Ann Intern Med 2002; 137:298-9.

11. Cass A, Cunningham J, Arnold PC, et al. Delayed referral to a nephrologist: outcomes among patients who survive at least one year on dialysis. Med J Aust 2002 177:135-8.

12. Avorn J, Bohn RL, Levy E, et al. Nephrologist care and mortality in patients with chronic renal insufficiency. Arch Intern Med 2002;162:2002-6.

13. Shah BR, Gunraj N, Hux JE. Markers of access to and quality of primary care for aboriginal people in Ontario, Canada. Am J Public Health 2003;93:798-802.

14. Newbold KB. Aboriginal physician use in Canada: location, orientation and identity. Health Econ 1997;6:197-207.

15. Martens PJ, Sanderson D, Jebamani L. Health services use of Manitoba First Nations people: Is it related to underlying need? Can J Public Health 2005;96 (Suppl 1):S39-44.

16. Falik M, Needleman J, Wells BL, et al. Ambulatory care sensitive hospitalizations and emergency visits: experiences of Medicaid patients using federally qualified health centers. Med Care 2001;39:551-61.

17. Brown AD, Goldacre MJ, Hicks N, et al. Hospitalization for ambulatory care-sensitive conditions: a method for comparative access and quality studies using routinely collected statistics. Can J Public Health 2001;92:155-9.

18. National Kidney Foundation. K/DOQI clinical practice guidelines for chronic kidney disease: evaluation, classification, and stratification. Am J Kidney Dis 2002; 39(Suppl 1):S1-266.

19. Aboriginal peoples of Canada: highlight tables, 2001 census. Ottawa: Statistics Canada; 2001. Available: www12.statcan.ca/english/census01/products/highlight /Aboriginal/Index.cfm?Lang=E (accessed 2008 Sept 30).

20. Manns BJ, Mortis GP, Taub KJ, et al. The Southern Alberta Renal Program database: a prototype for patient management and research initiatives. Clin Invest Med 2001;24:164-70.

21. Oliver M, Lok C, Shi J, et al. Dialysis therapy for persons with diabetes. In: Hux JE, Booth GL, Slaughter PM, et al., editors. Ontario: An ICES practice atlas. Toronto: The Institute for Clinical Evaluative Sciences; 2003. p. 165-80. Available: www.ices.on.ca/file/DM_Chapter8.pdf (accessed 2008 Sept 30).

22. Hux JE, Ivis F, Flintoft V, et al. Diabetes in Ontario: determination of prevalence and incidence using a validated administrative data algorithm. Diabetes Care 2002;25:512-6.

23. Ng E, Wilkins R, Perras A. How far is it to the nearest hospital? Calculating distances using the Statistics Canada Postal Code Conversion File. Health Rep 1993;5:179-88.

24. Pitblado JR, Pong RW. Geographic distribution of physicians in Canada: beyond how many and where. Sudbury (ON): Centre for Rural and Northern Health Research; 1999. Available: www.theruralcentre.com/CIHI\%20-\%20Geographic\%20Distribution\%20of\%20Physicians\%20in\%20Canada.pdf (accessed 2008 Sept 30)

25. Levey AS, Bosch JP, Lewis JB, et al. A more accurate method to estimate glomerular filtration rate from serum creatinine: a new prediction equation. Modification of diet in renal disease study group. Ann Intern Med 1999;130:461-70.

26. Nelson RG, Greene T, Beck GJ et al. Estimating GFR by the MDRD and Cockcroft-Gault equations in Pima Indians. J Am Soc Nephrol 2003;14:134A.

27. Poggio ED, Wang $X$, Greene $T$, et al. Performance of the modification of diet in renal disease and Cockcroft-Gault equations in the estimation of GFR in health and in chronic kidney disease. J Am Soc Nephrol 2005;16:459-66.

28. Levey AS, Coresh J, Greene T, et al. Expressing the MDRD study equation for estimating GFR with IDMS traceable (gold standard) serum creatinine values. $J$ Am Soc Nephrol 2005;16:69A.

29. Young TK. Review of research on aboriginal populations in Canada: relevance to their health needs. BMJ 2003;327:419-22.

30. Katz SJ, Hofer TP, Manning WG. Physician use in Ontario and the United States: The impact of socioeconomic status and health status. Am J Public Health 1996; 86:520-4.

31. Gao S, Manns B, Culleton B, et al. Prevalence of measured chronic kidney disease and survival among First Nations people. J Am Soc Nephrol 2007;18:2953-9.

32. Ifudu O, Dawood M, Iofel Y, et al. Delayed referral of black, Hispanic, and older patients with chronic renal failure. Am J Kidney Dis 1999;33:728-33.

33. Kausz AT, Obrador GT, Arora P, et al. Late initiation of dialysis among women and ethnic minorities in the United States. J Am Soc Nephrol 2000;11:2351-7.

34. Kazmi WH, Obrador GT, Khan SS, et al. Late nephrology referral and mortality among patients with end-stage renal disease: a propensity score analysis. Nephrol Dial Transplant 2004;19:1808-14.

35. Kinchen KS, Sadler J, Fink N, et al. The timing of specialist evaluation in chronic kidney disease and mortality. Ann Intern Med 2002;137:479-86.

Correspondence to: Dr. Brenda Hemmelgarn, Division of

Nephrology, Foothills Hospital, 1403 29th St. NW, Calgary AB

T2N 2T9; fax 403 944-2876;

brenda.hemmelgarn@calgaryhealthregion.ca 